\title{
A narrative inquiry into spatial experience: Learners' recollections from pre-COVID-19 classroom setting
}

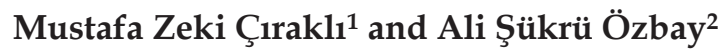 \\ ${ }^{1}$ Department of English Language and Literature, Karadeniz Technical University, Turkey (ORCID: 0000-0002-1760-3209) \\ ${ }^{2}$ Department of English Language and Literature, Karadeniz Technical University, Turkey (ORCID: 0000-0002-3421-0650)
}

\begin{abstract}
Many theories, techniques and strategies are concerned with the development of an ideal educational setting that enables learners to demonstrate growth and improvement. Research to date mostly envisaged the classroom setting as an external aspect of the educational medium and discussed it in terms of social interaction, communicative requirements, physical structure and services. The learner's spatial experience, however, needs to be explored from different perspectives such as spatial interaction and memory reconstruction. Moreover, the educational setting has undergone a critical change after COVID-19 pandemic lockdown. The significance of this study is that it explores the recollections of individual learners from the pre-COVID-19 classroom setting following their virtual setting (Adobe-Connect) experience. The study focuses on the learners' personal (subjective) memories rather than the objective description of the medium and draws on the critical difference between educational "setting" and educational "space". It raises questions as to the role of the classroom setting and spatial experience in learning and memory. The study also aims to examine the participants' recollections of the pre-COVID-19 classroom experience about the setting elements and objects as well as explores to what extent the classroom setting turns into an experiential space before and after COVID-19 pandemic. Qualitative measures were used within the scope of narrative inquiry to collect data in order to validate and confer the findings. The participants were two senior BA students at a Department of English Language and Literature (ELL) in Turkey. Their spatial experiences were explored through the participants' small narrative accounts about the pre-COVID-19 classroom and online virtual classroom. The results were discussed according to the spatial practice conceptualized within the theory of postromantic education, which argues that unless educational "setting" is transformed into educational "space", there would be no ground for experience and learning. The study revealed that the participants were both narrators and focalizers when they were talking about conventional classroom settings and treating the objects as carriers of emotions and stories. The participants reported that classroom objects were still vivid in mind, restored in the memory, and reconstructed in the imagination, which showed that the participants under consideration had a spatial experience and the classroom was transformed from setting to space. As regards the Adobe Connect virtual classrooms, the participant narrators were rarely focalisers, and the small narratives changed into narrative fragments, which shows that online virtual classroom is questionable in terms of spatial experience. The study concludes that the participants' small narratives are punctuated with the references to setting elements and objects in the form of emotive spatial experience and positive episodic memories. The indicators and verbal elements were loaded with psychological and experiential implications. The study presents the implications for applied linguistics and classroom research and makes suggestions for further studies.
\end{abstract}

Keywords: Classroom; Educational setting vs space; Online educational setting; Spatial experience; Applied linguistics

Article History: Submitted 2 September 2020; Revised 19 December 2020; Published online 30 December 2020

\section{Introduction}

\author{
Address of Corresponding Author \\ Ali Şükrü Özbay, PhD, Department of Western Languages and Literature, Faculty of Letters, English Language and Literature, Kanuni \\ Campus, 61080, Trabzon, Turkey. \\ $\triangle$ alisukruozbay@gmail.com
}

How to cite: Çıraklı, M. Z., \& Özbay, A. Ş. (2020). A narrative inquiry into spatial experience: Learners' recollections from pre-COVID-19 classroom setting. Journal of Pedagogical Research, 4(4), 508-531. 
Learners' experience with the classroom objects is not merely restricted to perceptions, sense perceptions or visual ability. Nor are these objects pure instruments to be utilized in the classroom setting. Leimanis-Wyat (2010), for example, suggests using "objects to inspire story-writing" and conceives setting elements as prompters or instruments (p. 45). Randall (2007), in his overview about how memory works, discusses learners experience in terms of the perception of the learner and envisages the objects as the source of "visual information" (p. 34). He argues that long term memory stores the visual information derived from the objects. He seems to be disregarding the spatial experience of the learner with the objects as such. In his model, working memory interprets visual information and uses it to construct visual images, thereby conveying them to the long-term memory. He is concerned with the storage of information, and the learner is a passive receiver in this model. The model accounts for the processes taking place in the mind yet does not explain what really happens on the side of the learner persona. A similar shortcoming is observed in experimental psychology, too, which gives priority to "visual attention", "selectivity", "object recognition" or "visual abilities" (Wixted \& Serences, 2018, p. 28, 755, 756). The participants in this study get beyond these limits as they have a genuine touch with the classroom setting and objects and develop a personal experience with them as well as developing an individual consciousness. The participants are so sentimental and enthusiastic about sharing their subjective experience with the classroom objects that their episodic memories call for overwhelming considerations into the understanding of the individual experience, and revealing how it is represented in their subjective consciousness represented through narrative accounts.

The significance of this study is that it explores the subjectivities of each learner about the classroom setting (learning space) rather than the objective description of the medium. The study draws on the classroom experience and recollections of the learners from the pre-COVID-19 classroom setting elements, foregrounding the difference between educational "setting" and educational "space" as well as poses critical questions as to what makes a classroom a part of learner's experience and memory. It also aimed to examine the students' recollections from the classroom setting, to explore to what extent the classroom objects still exist in the present memory, to question whether the setting has turned into an experiential space, to analyse the data produced in the participants' narratives with certain references to the classroom setting elements and to investigate the verbal indicators loaded with social, cultural, ideological, psychological and experiential implications for applied linguistics and classroom research as well as educational settings.

\subsection{Classroom as an Educational Setting}

A research held by Carmona, Carmona and Clarke (2002) stresses the effect of classroom setting on the students' achievement, showing that test scores are increased by $11 \%$ through the improvement of a classroom's physical environment. Classroom setting has so far been conceived mostly as a social organization and its physical design is mostly associated with technological equipment installed in the medium (Hutchison, 2004). There are 43 items on the checklist and 7 subcategories in a standard Environment Rating Scale (ERS) used to decide whether a classroom meets the requirements of quality. Among them are so many social and cognitive elements and teaching gadgets as well as classroom as a physical entity and a pool of objects. However, space is considered as the available place, and the setting elements and objects are of secondary importance. In the upper levels, students use desks, and the large medium stage is minimum or missing since there is a whiteboard plus smart board, projectors and tablets. Hutchison (2004), for example, proposes a "vision of dynamic space" and relates the idea to setting elements. In his book, he devotes a chapter to this dynamic space which is pre-supposedly based upon the issue of Environment and classroom design (pp. 77-100). This study, however, sets up from the premise that the classroom setting does only not exist as a spatial experience in the learner's memory, and the learners almost always experience estrangement with the setting and environment. Even though this idea sounds somewhat radical and as if roaming along with the extremes of ideas, the 
researchers can find significant elements in the narrative accounts of the students. In fact, a classroom setting should be a "learning space" as always suggested, but it seems that it does not serve for memory, thereby not serving for learning on an experiential level. Learning spaces, however, in which both children and adults learn, are meant to be classrooms and considered as essential educational foundations from preschools to universities. The classroom is almost always defined according to the external factors like distractions coming from outside. Instead, it can only turn into space where learning can take place and when the learner "particularizes" the setting elements and objects in the classroom. Some students make frequent references to objects when they are sharing their classroom experience (Çırakl1, 2020). These objects are carriers of emotion and memory constructs history, topos (space) and chronos (time) in narrative terms by using them and needs setting elements and objects. However, if there is no meaningful experience with these objects, they cannot take place in memory, and knowledge stored in the form of narratives is negatively affected by this. The learner's mind can overwhelm the distractions in the temporal progression of time, but it cannot process without space. Purely rational and abstract realm of the concepts are unachievable by most of the learners, and at least they have a spatial realm of the hardcopy books and pages. But after the turn of pandemic lockdown, space is redefined for the educational masses and it seems that adaptation will take longer than expected. Memory, without space, works upon a void bulk of signs and cannot store emotions triggered and carried by the objects.

\subsection{Transformation of Classroom Setting}

It is a fact that new classroom environments have the potential to change teaching and learning activities in ways hardly predicted only a decade ago. The construction of creative environments for learning does not necessarily mean the creation of a physical environment though there is a general consensus that the concept is largely used for the physical properties of language classrooms. Creating a new space of a learning environment does not only bring about better creativity and communication (Davies et al. 2013) but also it brings about the subjective interpretation of classroom objects as emotional constructs. This subjective means of classroom objects worth further investigation in terms of the reconstruction of objects around learners' emotions in a new classroom space. The transformation of the classroom setting from physical sense into a spatial organization is likely to create involvement and a sense of connection between the learners and the classroom objects. This is also called "experientality" in its broadest sense. The classroom objects, setting layout, sitting design and details of the decoration of the classroom setting have a significant effect upon the quality of the learning experience (Woolner, 2010). There is research showing that elements of colour and acoustics can decrease the effect of distractors, but the objects and their use, colour or acoustic variations can also be types of distraction. What is more, they are additionally important stimulators for memory. Mira et al. (2003) suggests that "the lighting and furniture likewise influence factors such as student attention span" (p.236).

The opinions of language learners and teachers towards the ideal classroom setting have attracted increasing attention in the last decade and many research-based studies have dealt with the issue from both language teachers' and learners' perspective. In a study conducted by DemirYildiz (2020), the researcher focused on the opinions of 22 foreign language teachers from 9 different schools about the arrangement of an ideal and efficient foreign language learning setting and found out that there were several physical problems in the existing classrooms, such as inadequate technological infrastructure, limited environment for the exhibition of visual materials and problematic seating arrangements. The underlying causes for this situation in the study were the lack of rich linguistic environment in terms of flexibility, high-quality and verbal input. The study concluded that in an effort to create ideal classroom setting, there is a need to sustain motivation and enthusiasm of learners by designing a classroom setting that is appealing to students and "that can attract students' attention using various layers of visuals and configurations" (Demir-Yıld1z, 2020, p. 42). Likewise, in another study by Stadler-Altmann (2015), 
the researcher investigated the influence of constructed environment on education and evaluated the learning environments in terms of school architecture, school design, culture, classroom architecture and classroom activities, beginning with the question of "Is there an influence of school or classroom buildings and space on education?" (Stadler-Altmann 2015, p.548). She specifically focused on the model developed by Moos, who emphasized the importance of "physical setting of a classroom for improving the student outcomes and that architecture and physical design can influence psychological states and social behaviour" (as cited in StadlerAltmann 2015, p.548). Her study concluded that classroom setting requires careful arrangements as well as innovation in classroom floor plan, furniture, stimulation of all senses, positive environment, and privacy areas. Yet another study by Cheryan et al. (2014) investigated the design of classrooms to maximize student achievement and the researchers supported the idea that rather than structural quality, classroom environment must contain signs that are based on the idea that students are valuable and should be able to use their full capacities in the classrooms re-designed for this purpose. For them, the design of the language classroom requires the consideration of other factors, "prompting educational attainment" (Cheryan et al. 2014, p. 10). Dela Rosa (2019) in his study of on physical learning environments and the academic achievement found that "lighting and ventilation, and learning area are considered as not significant, but classrooms should be designed in such a way that various technologies should be used effectively" (Dela Rosa. 2019, p.1). However, Kekare (2015) argued for the significant relationship between classroom physical environment and academic achievement. His study further claimed learning performance of the students is likely to increase when they are provided with suitable classroom environment such as a well- furnished classroom with various facilities. In support of this, Urtil (2016) suggested that provision of appropriate classroom environment is one of the most significant necessities behind higher learning performance and academic success. In his study of "Designing an Interactioncentred Language Classroom", Greer (2014) mentioned the significance of physical setting in terms of "physical comfort, audibility and the arrangement of furniture" (Greer, 2014, p. 47), adding that how language teachers use the space is likely to affect the learning in the classroom. The "space" consideration of Greer seemed to be again the physical considerations rather than the consideration of space as an experiential area. Regarding the features of creativity in creating space, Warner and Myers (2010) focused on several features of ideal classroom environment such as lighting, colour, decorations, furniture, resources, space considerations and class size. Similarly, his space consideration for a creative classroom included structural changes including high ceilings and few walls which are designed for fostering "openness, freedom of movement, flexibility and mobility" (Warner \& Myers, 2010, p.32). In spite of the fact that Warner and Myers' space configuration carries some elements of the classroom as an experiential space, he, for the most part, approaches "space" as a creative environment in the physical sense. Nambiar et al. (2017), on the other hand, focused on the influence of social setting on learning and learning space that fosters active experimentation in the new classrooms. By using premises of social constructivist approach by Vygotsky, they have claimed that learning occurs mainly through social interaction and problem solution and new learning spaces give the learners opportunities to solve the problems from a new perspective in a new learning environment other than the traditional classroom. The new classroom model according to them should be like a showcase where learners are constantly active in "brainstorming ideas, doing project work and constructing models" (Nambiar et al, 2017, p.31). Last but not least, Yıldız and Çakır (2013) evaluated the design of the language classrooms in the School of Foreign Language through observation and interviews with learners and instructors and found that there were basically seven problems associated with the classrooms. These problems were "sitting order, sound insulation, uncontrolled natural lighting, ergonomic storage for course materials, information accessibility, circulation and student quotas" (Yıldız \& Çakır 2013, p.281). The researchers considered "space" for educational activities as a "physical property" like the others. 
Based on various research studies conducted in the last decade regarding the ideal classroom setting summarized above, it seems that the physical qualities of language classrooms have been prioritized, and that there is a dearth of literature regarding the classroom as an educational setting and an educational space where learners' emotional needs are also met to some extent by turning the classroom space into an experiential one. The concept of experientiality occupied an important place in this current study since objective classroom setting should be translated to / transformed in / reconstructed in the subjective memory of the learner in the form of experiential space (Ç1rakl1, 2018). Experientiality is more concerned with "having genuine touch with the objects" and the setting requires to be kept, restored or recollected as images or subjective / spatial experience of the student. To explain this "spatial experience", it may be possible to draw on an analogy between temporal time (clock-time) and spatial time (experienced) time, two significant operational terms in narratology and narrative theory; the former refers to the mechanical temporal movement of the hands while the latter corresponds to the spatial experientiality. The learner can keep, carry the classroom setting in the form of an image (an amalgamation of emotions, feelings and sense perceptions): "Space is experiential whereas place is extensional and, therefore, is meaningful, functional and expressive. Space is human and hence classroom setting is infected with temporality, whereas space stirs experientiality (spatiality) and that space turns out to be both functional and expressive for the human-learner (not a student), who always retains a reflective and retrospective memory" (Ç1rakl1, 2018, p.135).

\subsection{Online Educational Space before and after COVID-19}

It is a fact that the educational environment has effects on the attitudes of the learners. In shaping the educational philosophy, the role of the classroom setting is significant. The design of the traditional classrooms (before COVID-19 pandemic outbreak) was based on the educational space which allowed face-to-face education for students in their fixed seating positions with more motivated students seating in front. After the COVID-19 pandemic period, however, the education settings and their physical learning spaces all throughout the world needed to be re-adjusted in various ways. This re-adjustment process has been made in the form of keeping distances between the learners and all other interested circles to protect them from the spread of the virus. Viner et al. (2020) most recently stated that physical distancing measures such as closing the schools would help prevent the spread and many countries in the world have taken precautions regarding the physical distance. In Turkey, days after COVID-19 cases were noticed, all schools and universities across the country were closed in mid-March as part of the measures to curb the spread of coronavirus. This immediate closure has changed the physical learning settings into their homes widely equipped with digital online tools such as Zoom, Google Classroom or Adobe Connect. This created, in return, new physical learning spaces for all learners and this study investigated the influence of these virtual mediums on the learners in terms of subjective experientiality.

\subsection{Online Educational Tools Used in the Study}

The integration of technology into the educational setting has become crucially important especially after COVID-19. The digital technology is now widely used by the stake-holders. Adobe Connect, as a digital technology tool, was used in the study due to its potential to contribute to teaching-learning processes. Adobe Connect enables instructors to host an online session and the teachers and the students may be in different locations in this online meeting. Especially after the distance education process gained huge momentum in recent times, it has been seen that Adobe Connect proved to be especially helpful in conducting courses with the remote learners. The tool is used as a distance learning course medium across devices, including mobile devices and users (teachers, instructors) seized the opportunity to share files, whiteboards, and host resources as well as offer interesting content delivery. The software permits any file extensions (Erturan et al., 2012), enables users to download files uploaded by the host or other users, makes it possible to zoom during screen sharing and to control the users' desktop through share desktop. It is also possible for the host and other authorized users to start whiteboard meeting function in which it becomes 
possible to create texts, line, square, circles and other drawings simultaneously during and after the meeting by saving the meetings (Şen et al., 2010). Saving option is important since users have the chance to see the courses they missed at multiple times. Adobe Connect enables its users to save the meeting for offline watching and to link the programs archive.

\subsection{Importance and Aim}

The significance of this study is that it explores the individual learners' recollections of the preCOVID-19 classroom setting after the dramatic shift to the virtual medium/setting (AdobeConnect). Considering the research niche as to the spatial perspective, the study focuses on the spatial experience and how it serves for the episodic (positive) active memory, mind and imagination of the learners. The study draws on the learners' subjective memories rather than the objective description of the medium and is original in that it integrates the terminologies of pedagogy, narratology and narrative inquiry into analyzing the narratives produced by the learners. Regarding the critical difference between educational "setting" and "space", the study raises questions as to what makes involvement in a lesson in a conventional classroom setting as part of learners' spatial experience and memory.

The aim of this study is to raise awareness on "spatial interaction" since interaction, an essential phenomena in the educational settings, is conceived as having one social dimension by a considerable number of teachers. Interaction, as a critical notion in life, in education and in classroom setting has two crucial aspects: Social interaction and spatial interaction. McLaren and McKeever (2019) stresses the "significance of physical contexts and human interactions" in educational contexts (p. 60) and Garnet (2020) suggests that the setting and the objects are not "static" but "piece[s] of material culture in a constant state of becoming" (p. 648). Every individual learner at every stage of education is caught up in endless encounters, indicating a moment of social or spatial interaction in educational settings. Hence, research devoted to spatial interaction in educational settings should not be restricted to traumatic cases, the cases of teaching children and young learners, or the cases of the disabled. Garnet (2020) invites us "to reflect on the meaning we give to classroom objects, the agency these objects possess (p. 648)", implying that such increased awareness of spatial interaction may help teach empathy, one of the critical objectives of education. Moreover, the temporal and cultural arrangement of the learning settings have been considered so far, but after COVID-19 lockdown, we have seen that the dramatic change emerged in space. Therefore, the educators should reconsider the significance and role of setting as "place and space" and contemplate as to how we can transform "virtual settings" into beneficial "learning spaces." In a nutshell, the study aims (a) to examine the participants' recollections of the Pre-Covid-19 classroom setting elements and (b) to explore to what extent the classroom setting has turned into an experiential space after COVID-19. The researchers' hypothesis is that the objects in the classroom setting are essential in memory-making, and any object in this setting is a means of transformation from setting to experiential space. The central premise of the study is that learners may feel more human when they can recollect, restore, reconstruct the classroom setting in the form of refreshed spatial experience in their minds, memory and imagination. (c) to increase the teachers' awareness of "spatial interaction" since interaction has two essential aspects: social and spatial. The study helps the teachers to reconsider the sensitivities of the learners towards the setting elements.

The study designed a qualitative inquiry into how the physical setting elements take place in the narratives that represent retrospective memory of the learners. The following questions were asked in the light of the narrative inquiry research.

1. What is the role of the objects in the classroom setting in memory-making?

2. What is the role of the objects in the classroom experience?

3. What is the role of the objects in experiential learning?

4. What is the role of spatial experience in the reconstruction of the temporal classroom setting in the memory, mind, and imagination? 
5. How does it feel to lack social and spatial interaction in the online virtual classroom?

\section{Method}

\subsection{Research Design}

We used a thematic organization and evaluation model developed by Labov (1972) as a linguistic methodology and considered it as a simple and useful method in the stratification of the data produced by the narrator-participant (Smith, 2000). The re-constructed narrative account about the past was classified and questioned by using the following questions: "What was it about?; Who, What, When, Where?; What happened?; So what?; What finally happened?". These questions also gave the developmental stages of a narrative comprising exposition (abstract), orientation, complication, evaluation, result and coda. The present study also provided a preliminary prompt question: "What do you remember from the pre-COVID-19 classroom?" The participant's free narrative was not obstructed even when it digresses. The researchers processed the raw data and selected the narrative parts about the same or similar topics or objects. Borrowing terminologies from Narratology, Experiential and Spatial Time theories, the results were discussed according to the spatial practice conceptualized within the theory of postromantic education, which argues that unless educational "setting" is transformed into educational 'space', there would be no ground for experience and learning (Çırakl1, 2018, p.134).

\subsection{Classroom Setting and Participants}

Historically set in 2017 in line with the standard with desks arranged in two columns, the preCOVID-19 classroom setting included a standing desk for the professor at the front (see Figure 1). The furniture is in red has an overall colour effect: The doors and the chairs wore red. The walls and desks were white. The lightning was relatively good with warm fluorescent lights and also available were the sun bulbs. The participants stated that they liked their classroom particularly for colour selection and for physical isolation and concentration with its agora-like design of escalating desks towards the back. The doors behind the students are at the back and top. There was a considerable physical room at the front and even though the classroom desks were arranged in rows or columns, but the terrace-shape of the classroom made it possible to produce an inadequate effect of $U$ design interaction. Furthermore, each desk included five chairs to create "clusters" or "groups", which helped to encourage interaction and participation in group activities. Colour can be considered another significant factor, but even though the students liked the classroom, particularly for the colour selection, how it is reconstructed or exists in their memory and narrative accounts is questionable. The study explored whether the colour is as significant an asset in the classroom setting as is in the space in the memory.

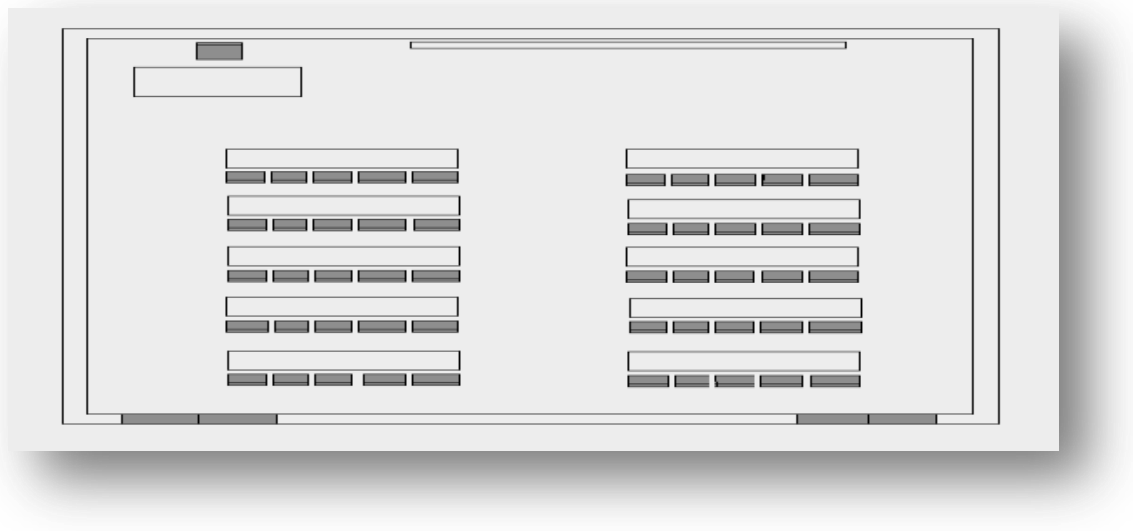

Figure 1. Classroom Setting 
In the study, we used purposeful sampling in order to select the two student participants and the specific strategy was criteria sampling (Miles \& Huberman, 1994). The two participants met the criteria required for the study.

1. Provision of narrative elements

2. Taking the "ELL3000-Contemporary Literary Theory" at the time of data collection (2020 Spring) / [The participants had enrolled in several literature courses including British Poetry and British Drama before]

3. Interested, attending, interactive and collaborative students according to the attendance sheet and the researchers' end-term evaluative remarks and assessment documents

4. Proposed by their undergraduate supervisors as candidate students who demonstrated a passion for learning and developing themselves academically

5. Years of study

The first criterion was selected on the basis of narrative elements provision. These two participants were selected because their narrative accounts met the essential elements of storytelling offered by Labov and provided the researchers with "accounts of experience" (Bamberg \& Georgakopoulou, 2008). The second criterion was the name of the course they were taking. The participants were asked to provide their narrative accounts based on the content of this course. The third criterion was that both participants were interested, attending, interactive and collaborative students according to the attendance sheet and the researchers' end-term evaluative remarks and assessment documents. Fourth, both participants were motivated to tell voluntarily their stories and share their personal experiences. The final category was the years of study of the participants. Both participants were experienced third-grade students with similar grades, routines, curriculum, and academic development aspirations in the content area required by the course instructor. Table 1 below shows the demographic profiles of the participants.

Table 1

Participants Demographic Profiles

\begin{tabular}{lll}
\hline Characteristics & P1 & P2 \\
\hline Gender & Female & Female \\
Age & 21 & 21 \\
Years of study (University) & 3rd grade (junior) & 3rd grade (junior) \\
Level of education & Undergraduate & Indergraduate \\
Type of Classroom & Inclusion & Inclusion \\
The course taken & ELL3000 Contemporary & ELL3000 Contemporary \\
& Literary Theory & Literary Theory \\
\hline
\end{tabular}

\subsubsection{Researchers}

One of the researchers was teaching literature at the Department, but the students were taking other literature and language courses, too. The researchers taught British Poetry in the pre-COVID19 era and teaching Literary Criticism after COVID-19 lockdown. The focus of this study was the classroom setting, setting elements and objects and the research question was about the classroom setting, not the courses. The students were not restricted to telling about specific courses.

\subsection{Data Collection Tools}

In the scope of the study, "diaries" and "narrative interviews" were used as data collection tools. The small narratives telling us about the learners' personal experience were used in the analysis. Ethical approval and consent letters were provided. Once having the consent of the participants, the diaries were examined and the researchers dealt with the minimum number of the sampling size (6 sample narratives from 2 participants) so that they could adequately evaluate and analyze the data in depth through theoretical reading and interpret the narratives about particular objects 
under consideration. One further reason for the selection was that the samples were categorized according to the objects. They were selected by the participants, not by the researchers and the narratives and narrative fragments were grouped regarding the objects narrated. The narrative accounts that met the criteria of "storytelling elements" and "homogeneity" (Kuzel, 1992) were considered.

Benson (2014) highlights the importance of narrative studies about learners' retrospective memory. The critical question about their past and present experience aims at exploring the representation of classroom setting elements in memory. As Benson (2014) suggests, this study draws on the small narratives providing a broader perspective on individual classroom experiences, thereby unearthing significant contextual and psychological variables that explicate spatial practice. This can be more of an issue explored by narrative inquiry, states Benson (2014), than might be possible by other methods. Hence, in narrative inquiry, the semi-structured interview transcriptions were used. The subjects were free to tell their experiences on various events in their lives. The researchers reviewed the narratives with the help of the participants and revised ambiguities in line with their suggestions to avoid confusion and misunderstanding. The researchers carefully took notes of the oral accounts, thus "prioritising the story teller's perspective rather than imposing a more specific agenda" (Anderson \& Kirkpatrick, 2016, p. 1).

Diaries were used in the study. The student diaries included narrative parts and provided the researchers with the raw data related to the instances of time, space and the subjects' individual experiences in their lives. In other words, we collected data related to the instances of time the subjects experienced in their classroom setting. By this way, we tried to capture the significant moments of their classroom and physical environment. Recollections from the pre-COVID-19 classroom setting elements and objects were the focus of the study. The narrative accounts and fragments about the classroom objects were used to explore the spatial experience and spatial interaction of the learners. The diaries, as suggested by field literature, provided us with a series of descriptive events or personal accounts of an event and required the participants to make selfreports repeatedly over time in narrative form (Bolger, Davis \& Rafaeli, 2003).

After the diaries were categorized according to the objects chosen by the participants, the small narratives and stories were selected concerning homogeneity and theme resemblance. They were asked to write about their recollections from the pre-COVID-19 classroom setting and their online virtual setting, in terms of the physical environment, classroom elements and objects (spatial experience). Similar questions were raised in the interviews as presented in Table 2.

Table 2

Diary and Interview Contents

\begin{tabular}{|c|c|c|}
\hline Diary Content & & Interview Content \\
\hline $\begin{array}{l}\text { 1. What is the role of the objects in the classroom } \\
\text { setting in memory-making? }\end{array}$ & $\rightarrow$ & $\begin{array}{l}\text { 1. What do you remember from the pre- } \\
\text { COVID-19 classroom setting? Which particular } \\
\text { object? }\end{array}$ \\
\hline $\begin{array}{l}\text { 2. What is the role of these objects in the classroom } \\
\text { experience? }\end{array}$ & $\rightarrow$ & $\begin{array}{l}\text { 2. Can you tell us about your experiences of the } \\
\text { classroom as a physical learning environment? }\end{array}$ \\
\hline $\begin{array}{l}\text { 3. What is the role of these objects in experiential } \\
\text { learning? }\end{array}$ & $\rightarrow$ & $\begin{array}{l}\text { 3. Can you tell us about a memory with an } \\
\text { object? Do you remember the lesson? }\end{array}$ \\
\hline $\begin{array}{l}\text { 4. What is the role of spatial experience in the } \\
\text { reconstruction of the temporal classroom setting in } \\
\text { the memory, mind, and imagination? }\end{array}$ & $\rightarrow$ & $\begin{array}{l}\text { 4. Can you tell us about the online virtual } \\
\text { classroom setting? }\end{array}$ \\
\hline $\begin{array}{l}\text { 5. How does it feel to lack social and spatial } \\
\text { interaction in the online virtual classroom? }\end{array}$ & $\begin{array}{l}\rightarrow \\
\rightarrow\end{array}$ & $\begin{array}{l}\text { 5. Tell us about your classrooms in the pre- } \\
\text { COVID- } 19 \text { and post-COVID- } 19 \text { period? } \\
6 \text {. What does the new classroom space } \\
\text { represent for you? }\end{array}$ \\
\hline
\end{tabular}

A possible risk involved in the narrative inquiry was losing control as to the flow of the interviewing process due to emotional or sensitive issues (Reissman, 2008). Hence, the interview 
consisted of two sessions, these being narrative phrase and follow-up. First, we handed out (via email) and let them think about their spatial experience. They were given complete freedom at this stage. For some time later, the researchers started the narrative follow-up. At this stage, we reread their stories together and asked whether they wanted to add something or to delete some parts. After their oral and written consent, the researchers proceeded with the analysis.

The researchers checked the results according to the field texts (Coffey \& Atkinson, 1996) based on their teaching experience. Researcher A. kept an ethnographic field text including the descriptions of the activities, sketch transcriptions, stage directions, diagrams, transcripts of conversations, list of classroom objects, a material designed of classroom objects and other field notes so that he can improve social and spatial interaction in the subsequent sessions. The researchers observed that the narratives were appropriately corresponding to the classroom activities and the references were correct. They realised that the narratives were authentic and representing their experiences. These field texts helped validate the data pertaining to the recollections of the classroom settings. The researchers paid attention to the relational aspects of these field notes, and actively involved in understanding their personal memories about classroom setting. The researchers hypothesized that the findings would illuminate the critical difference between educational "setting" and "space". As a result, the data composed with a focus on "temporality, sociality and place" (Clandinin \& Huber, 2010, p. 12). They used narratological terminologies of "narrating / telling, focalizing / perceiving, emotive discourse" to identify the verbal indicators used in the discussion.

\subsection{Procedures}

The procedure followed in the study is given in Table 3.

Table 3

The Steps in the Study

The research problem was formulated after the observation that the students were taking an

Step 1: online Adobe Connect lesson reported missing / longing for their classroom and classroom sessions.

One of the researchers was the course instructor and asked the students about their classroom

Step 2: memories. The question was replied with many details through written narrative accounts (in the native tongue) related to the objects particularly the ones the students used in the classroom activities and the objects they had a particular experience with.

Step 3: The objects they remember were of great significance for the researchers and they set up a hypothesis upon this observation.

They used a thematic organization and evaluation model developed by Labov (1972) as a

Step 4: linguistic methodology and considered it as a simple and useful method in the stratification of the data (personal narrative accounts) produced by the narrator-participants.

The researchers processed the raw data and selected the narrative parts about the same or similar

Step 5: topics or objects. Borrowing terminologies from Narratology, Experiential and Spatial Time theories, the results were discussed according to the spatial practice / spatial experience conceptualized within the theory of postromantic education.

The re-constructed narrative account about the past was classified and questioned by using the

Step 6: following questions: "What was it about?; Who, What, When, Where?; What happened?; So what?; What finally happened?

Step 7: The semi-structured interview transcriptions were used. The participants were free to tell once again their experiences on various events in their lives. They were allowed to add or omit. Step 8: $\begin{aligned} & \text { The researchers cross-checked the results according to the field experience and field notes and } \\ & \text { tested the validity and reliability of the data. }\end{aligned}$

Step 9: Data from the diaries and interviews were categorized under various thematic units and analysed using theoretical terminologies of the theory of postromantic education and narratology.

Step 10: The obtained results were discussed, and the conclusions were added, and the necessary implications were drawn. 


\subsection{Data Analysis}

This study investigated the elements of the classroom and how it took place in the memory of the students. The research aimed to understand how the students processed their experiences into meaningful narratives and how memory worked upon the objects in the classroom. Since Narrative Inquiry questions the idea of data-gathering, the study emerged in a very authentic sense of spontaneity, and these narratives are not "pre-designed" for the research. The data, as suggested by the essential premises of the method, promised utmost subjectivity and merely questioned the idea of objectivity. The learners' narrative accounts through diaries provided the researchers with significant knowledge about their subjectivities. These narratives illuminated the participants' constructed and perceived memories, as Bruner (1990) suggested earlier. Their nonneutral narrative, including storytelling elements, was more precious for the researcher as it enabled them to look "within". These narratives were hardly rhetorical and they were telling their stories and sharing their memory and imagination in a way that the researchers could see the existing picture in the minds of the participants. Even though any first-person narrative is technically and theoretically unreliable, the researchers considered the factors and tried to control them through post instruments. As Bruner (1990) suggests, the participants did not make references to clock-time (temporal time), instead, they told us about how they experienced duree (spatial time) in Bergsonian sense (Polkinghorne, 1988, p. 132). The narrative inquiry incarcerated the emotion and impression of the moments experienced in a particular setting or space, rendering the object/event in history a spatialized memory/image. In other words, passive setting elements were transformed into active spatial memories in the form of stories, imbued and infused with the covert effect to be expressed by the participant as a storyteller. The essential concepts in narrative research were the memory and the experience of time and the present study aimed to investigate time as recollected from the past and time as reconstructed in the present (Le Goff, 1992).

An essential number of small narratives were selected as they included storytelling elements. These were the stories from life. The elements (codes to be used in the qualitative analysis) provided by Labov are as follows: "an account of experience consisting of an abstract, orientation, complicating action, resolution, evaluation, and coda" (Labov (1972, p. 155); and the small stories were "narratives-in-interaction or more fragmentary accounts of experience" (Bamberg \& Georgakopoulou, 2008). So, data collection (diary writing) pointed to a convenient sampling since the narratives from the diaries of the volunteer students were used. The study analysed 12 small narratives from 2 participants about 4 conventional setting elements (door, wall, board, desk) and 1 virtual setting (Adobe Connect). As a qualitative study in nature, the study revealed the subjectivities of individual learners (Cresswell, 2007) rather than being a holistic descriptive study.

For the data analysis, a thematic organization and evaluation model developed by Labov (1972) was used. The raw data (The Told) was reconstructed from "The Told" and the storyline was reordered chronologically or conceptually. The two participants were not linear thinkers, and they zigzagged with their stories depending on what they believed was important for the moment. When we faced with such problems, we rearranged "the told" from the interviews, diaries and field texts into coherent stories and came up with a reconstructed story which became the "narrative for further analysis" (Mishler, 1995, p. 95).

The narrative account produced in Turkish were translated by the researchers. The translated versions of the narratives were also revised in line with suggestions of the participants, and necessary amendments were done together to avoid confusion. The phone interviews made with students A and B entailed careful revision, control, discussions and confirmation of the previous responses. The researchers asked for confirmation for the data shared through the interviews and diaries from the two participants and it was ensured that there was a strong convergence between the data sets. 


\section{Findings}

Narrative analysis, the sentences or clauses under examination were numbered to be referred in the further analysis and discussion sections. The use of brackets is a technique to avoid rewriting each sentence or phrase that might be crowding the paper.

"P.A" and "P.B" stand for the "Participant A" and "Participant B". These codes were used instead of giving the participants different names. P.A. was a female student and particularly interested in taking the course. Her accounts of the longings for the pre-COVID-19 classroom atmosphere inspired the researchers to conduct the study. P.B. was the other female student who was also interested in taking the course, and she produced long and sometimes diverging responses to the questions.

\subsection{Diaries (Participants' Diaries A and B)}

The participants' stories revealed emotions as well as comprised the elements of setting, time, characters, point of view and perspective. It was seen that the classroom was more of a space than a setting, and its existence in the memory of the participants was deeply implanted.

The small narratives below [1], [2], [3] produced by the participants (Table 4) indicate that the classroom setting as a physical setting, an environment and a social medium was transformed into certain objects. The student's spontaneous response to the initial prompt "what do you remember of Krashen (the unofficial name of the classroom)" was "the red door: [1] "Whenever I think about the old days, my classroom, I simply remember the red door." [2] Krashen, the unofficial name of the classroom dedicated to a linguist and the colour of the door are significant indicators. S/he stated that "[4] That colour, maybe, was a stimulator for me." The participant lays emphasis on the colour and seems aware of its stimulative power on the memory. S/he then remembers what they studied in the classroom in [5], where the participant remembers how s/he processed the empty form of information into practical knowledge. The participant's narrative reveals how s/he insists on his/her use of the red door as a metaphor in [6], which indicates a meaningful longing for the previous classroom.

Table 4

P1.A. 1: Representation of Memory (Door)

\begin{tabular}{ll}
\hline Student & Excerpt \\
\hline P1.A.1 & [1] Whenever I think about the old days, my classroom, I simply remember the red \\
& door. The name of the classroom was Krashen [the room was dedicated to the \\
& theoretician]. [2] [3] The colour of the door was red. [4] That colour, may be, was a \\
& stimulator for me. [5] We studied metaphor in the lesson and I recalled the teacher \\
& saying that the door of this classroom can be a very good metaphor. [6] May be for \\
& this reason I started to take the door as metaphor. [7] It can be funny but... as I \\
& approached the classroom, I always felt a bit confused. [8] All of a sudden would \\
& start a mind game whether it would be a happy session or a boring.
\end{tabular}

As regards the narrative produced about the virtual classroom in Table 5 below, [1] and [2] indicate that the memory is alive. Narrative section [3] goes further and signifies an emotive response and a kind of longing, if not mourning, for the loss of the classroom: "That door? The doors of my classrooms..." The participant is seen to have adopted an emotional tone in his/her expression of longing for the old days. The participant explains: "[4] To be honest, I can write a poem for the door..." His / her use of personification in [4] is significant. Even though the participant talks about the virtual classroom, s/he is still under the influence of "metaphor of a red door". The following words about Adobe Connect demonstrate practical issues in the clock-time: "[5] After Adobe Connect days... [6] In the beginning is a high stress and anxiety as to whether I can connect..." These words indicate the stressful daily routine of the virtual class. The participant switches off the mode of practical evaluation of the tool. His/her mention of in "[7] Psychological 
exhaustion" does not give any personal and particular information about his/her experience. Rather, s/he talks about the features of the technological tool and connection problems to the virtual setting. And he ironically states there is no class at all: "[8] Where is the classroom? Lying on the sofa... [9] I don't know?"

Table 5

P1.B. 2: Representation of Memory (Door)

Student Excerpt

P1.B. 2 [1] What about now? I really never thought one day I would miss the Krashen's door? [2] I would miss the moments when I approach it. [3] That door? The doors of my classrooms... [4] To be honest, I can write a poem for the door... After Adobe Connect days... [5] In the beginning is a high stress and anxiety as to whether I can connect... [6] Psychologically exhausted I start the lesson. [7] Where is the classroom? Lying on the sofa... [8] I don't know? I admit that I should concentrate but I cannot. [9] There are so many distractors.

As to be seen in Table 6 below, [1],[2],[3] show that the participant remembers and stresses the image of the door, and its colour took place in the narrative. The door this time is recollected as course material in [4]. The participant's story about how it became a course material reveals that the participant was involved in the event and setting thanks to the object, which is still alive in his/her memory. The participant says in [5] that it was "an unforgettable moment". [6], [7], [8] reveal his/her irritation of being "monitored", which is associated with the door.

Table 6

P2.A. Representation of Memory (Door)

\begin{tabular}{ll}
\hline Student & Excerpt \\
\hline P2. A & [1] When I think about our classroom... I remember so many things... [among which \\
& is] the door... [2] It was a red door and sometimes we used it as a course material. [3] \\
& Firstly I remember the door because I have an unforgettable moment with it: [4] One \\
day our topic was "gaze" and "monitoring" [two important concepts in literary \\
theory] and our teacher asked a friend to go out behind the door and to look through \\
the door (there was small rectangular windowpane from top to bottom). [5] The \\
lecturer and my friends knew about it. [6] It was strange to be "monitored" by \\
another "gaze" upon you. [7] Our friend was like a surveillance camera then, and we \\
got irritated in a way. [8] I still remember the feeling.
\end{tabular}

Table 7 below shows that in [1] and [2], the participant refers to the previously told story of "gaze and monitoring". S/he compares the experience of a virtual classroom with his/her previous experience: "[2] What is more interesting is that I feel as if we were all "monitoring" our teacher." [The participant was noted to be still laughing at the scene in the telephone conversation]. In [3],[4],[5] s/he switches to a mode of remorse and mourning and empathy with the lecturer complaining about the lack of interaction in a virtual classroom with cameras and microphones are mostly off. [6] We all see the teacher, but he cannot see us." [10] indicates the participant's emotional needs. It is seen that any word in the chatbox is a "carrier" of emotion. 
Table 7

P2.B. Representation of Memory (Door)

\begin{tabular}{ll}
\hline Student & Excerpt \\
\hline P2. B & [1] When it comes to COVID distance education days... [2] I recollect my classroom and \\
& am longing for "physically" connected. [3] What is more interesting is that I feel as if we \\
& were all "monitoring" our teacher. [4] The door or window? [5] Not really, through our \\
& screens. [6] The students' cameras and microphones are off. [7] We all see the teacher, \\
& but he cannot see us. [8] The helpless teacher and the careless students... [9] I enjoy It \\
& sounds so weird. [10] Interaction is so restricted. [11] Still, we have a very interactive chat \\
& box. [12] A camera is not worth a door.
\end{tabular}

The participant's personification is significant in [2] in Table 8 below. Here, the verbal indicators: "our poor and devoted whiteboard" and "smiling..." reveal s/he feels sympathy towards the whiteboard. [3], [4], [5] show that the whiteboard is a carrier of emotion, whose mention of creative drama sessions does not only reveal his/her involvement in the sessions but also his/her active memory. From [6] to [13], the participant tells us about the whiteboard and how it was used as an instrument.

Table 8

P1.A. Representation of Memory (Whiteboard)

\begin{tabular}{ll}
\hline Student & Excerpt \\
\hline P1. A & [1] Whenever I think about the old days, my classroom, I also remember our \\
& whiteboard... [2] our poor and devoted whiteboard... [3] I feel like smiling... [4] It was a \\
& portable one. [5] The teacher would use it not only for writing but also for other reasons. \\
& [6] As it was a portable board, we frequently used it as a staging element during Z... \\
& Hoca's creative drama sessions. [7] Yes, I really would love drama, even though you \\
& were not on the stage, as an audience you would love it. [8] I experienced dramatic irony \\
thanks to our whiteboard. [9] On the left the teacher told us about sonnet 130, for \\
example, on the right side of the separator (the white board) two of my friends were \\
having make up. [10] It was fun. [11] We could see both sides, and it was dramatically \\
ironic. [12] And in the parodies, our whiteboard was pretty useful. [13] One day, there \\
were Robert Browning's Duke and his famous Last Duchess were at both sides, it was so \\
funny. [14] I can never forget about those scenes, then revives my classroom lively and \\
energetic and [15] I remember the moments of my humble awakenings!
\end{tabular}

As for the Adobe Connect Whiteboard, the participant in Table 9 evaluates the virtual tool and $\mathrm{s} /$ he tells us about the efficiency or drawbacks of the Adobe Connect. S/he states that s/prefers the Adobe Connect whiteboard to teachers' using "dull and dumb ppt slides" [3]. It is seen that the participants are more concerned with/about the practical use of the tool. S/he says technological gadgets and tools can be useful and efficient. Then s/he switches to talking about the whiteboard used in the classroom setting, the past activities and how the whiteboard was used as a "décor" in a drama activity.

Table 9

P1.B. Representation of Memory (Whiteboard)

\begin{tabular}{ll}
\hline Student & Excerpt \\
\hline P1. B & [1] When it comes to the Adobe Connect Whiteboard... I find it very useful. [2] One of \\
& the best options for the teachers if they prefer telling and showing rather than using dull \\
& and dumb ppt slides. [3] I think the students like to see action happening, to watch the \\
& teacher thinking... [4] I mean the process of writing and thinking... I do. [5] Even the \\
& teacher's spelling mistakes in the whiteboard is preferable to me than a perfect \\
& powerpoint! [6] And, as you may guess, you cannot use an Adobe Whiteboard as a \\
separator in a drama activity nor as a mast with sail in a "Rime of the Ancient Mariner" \\
reproduction!
\end{tabular}


The participant tells us his/her habitual experience of keeping a notebook in Table 10 [not a computer, literally a notebook]. S/he is aware that the notebook is a kind of portable classroom space for him/her. S/he says: "[8] Then I have come to realize that my notebook was my classroom." The participant talks about the significance of taking notes, touching the pen and paper, keeping a notebook or a journal. S/he refers to the puzzle in [9] and [10]: "I condense and preserve the classroom in my notebook. My notebook does not only comprise information or the knowledge I gained during the class it also comprises my feelings..." S/he uses another reference to a character in literature.

Table 10

P2.A. Representation of Memory (Whiteboard)

\begin{tabular}{ll}
\hline Student & Excerpt \\
\hline P2. A. & [1] What else I remember from our classroom... Of all the objects, gadgets or elements in \\
the classroom, it was our portable whiteboard, thanks to which I could keep a notebook \\
in the lessons. [2] The whiteboard was a kind of moderator for me, moderator and \\
motivator, [3] therefore I liked the teachers using the whiteboard rather than projectors. \\
[4] It is something else. [5] Particularly when the teacher is using it efficiently and simple. \\
[6] It is warmer. [7] I always keep a detailed and neat notebook for my classes. [8] Then I \\
have come to realise that my notebook was my classroom. [9] I condense and preserve \\
the classroom in my notebook. [10] My notebook does not only comprise information or \\
the knowledge I gained during the class it also comprises my feelings... [11] I don't \\
know how to say it but when I open the notebook I directly get into my classroom as if I \\
were in the classroom... [12] all the things flowing through my mind like Joyce's Eveline \\
standing before the windowpane... [13] I just smell, you guess, another "cretonne".
\end{tabular}

Picture 1. Recollections of the classroom

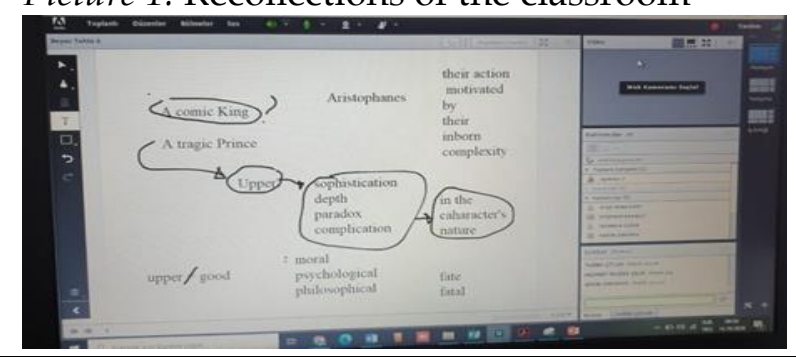

The narrative sections [1], [2], [3] in Table 11 show that the participant is disappointed with the virtual medium. S/ he [5] refers to the factors of efficiency as a technological tool. The participant is longing for social interaction and the conventional classroom: "[6] I miss my teacher writing on the board with a terrible board marker about to run out...". This participant is self-conscious about what s/he really needs: "[7] The participant tells us that "once the virtual session is over, I close my eyes, and I cannot remember any scenes... but the scenes from the pre-COVID-19 classroom." $\mathrm{S} /$ he says she cannot imagine a scene in a setting.

\section{Table 11}

P2.B. Representation of Memory (Whiteboard)

\begin{tabular}{ll}
\hline Student & Excerpt \\
\hline P2. B & [1] As for the white board after COVID, I mean the one offered by Adobe Connect... [2] I \\
& don't know how it happens but I immediately remember the white board in the previous \\
& classroom. [3] Then follows disappointment of course. [4] This one is an effective one, \\
& some teachers use it very well... but ... [4] Adobe Connect whiteboard provides me with \\
& mere knowledge, the notes made by the teacher but my feelings... [5] I miss my teacher \\
& writing on the board with a terrible board marker about to run out... [6] Once the virtual \\
& session is over, I close my eyes, and I cannot remember any scenes... [7] but the scenes \\
& from pre-Covid classroom.
\end{tabular}


Narrative parts [1], [2], [3] in Table 12 surprisingly mentions the memory of the wall, so-called Krashen Room. [4], [5] personify the wall, and the scene is vivid and his/her memory is still active. The participant shares a memory of a classroom activity as to "[6] the impressions of the objects in the classroom" and "a moment of touch to/with the walls." In [7], [8], [9], [10], [11] she goes on telling the story of their "touching and feeling the wall" experience. [12] shows that they had fun. S/he tells us about how they "listened to" the wall [13]. S/he feels like hearing the echo of the teacher's voice: “The dumb wall!" In [16], [17] s/he explains why she was so affected by the quote from a literary work again. [17] It was strange. Narrative part [18] tells us how s/he became more sensitive to the environment and setting. S/he [20] makes another reference to Wordsworth and says: "The wall heard us, I believe, but nobody."

Table 12

P1.A. Representation of Memory (The Wall)

\begin{tabular}{ll}
\hline Student & Excerpt \\
\hline P1. A & [1] And I remember the wall... [2] It might be surprising that I really remember the wall... [3] \\
Whenever I think about Krashen [the unofficial name of the classroom], the wall is among \\
what I remember... and the day when I first met it! [4] Particularly the moment when I \\
became aware of the fact that I had not seen it although I everyday passed by the wall. [5] Of \\
course, I did not come up with that idea myself. [6] One day, Z... Hoca asked us about the \\
impressions of the objects in the classroom and asked whether we had had a touch with the \\
walls. [7] The idea first sounded funny. [8] Frankly, it was funny and the teacher, I thought, \\
just wanted to draw our attention as a part of warming up, or something... [9] Then, the \\
teacher said he was serious, and it was important to touch the walls to feel the classroom. [10] \\
A friend of ours stood up (he was invited by the teacher) and got to the wall. [11] The teacher \\
asked him to put his check on the wall, feel the cool stone and silently speak to it. [12] We all \\
laughed then... And the teacher had us all go to the wall, we all touched our hands to the \\
wall, tried to feel it... [13] Listened to the wall putting leaning eyes to touch to the wall... [14] \\
I thought it would be weird and a bit stupid... [15] But still echoed the voice of the teacher: \\
"The dumb wall!" [16] In another lesson we had studied Beckett's the Dumb Waiter and it \\
sounded ironic to me. [17] It was strange. [18] What is more surprising happened later. [19] \\
All through the following days, I "saw" the wall, sometimes I even said hello! [20] What is so \\
interesting is that now I remember our classroom, the moment we all touched the door, [21] \\
and all of a sudden comes to my mind Wordsworth's lines, not only the lines but the scene \\
when we rehearsed the poem to the wall. The wall heard us, I believe, but nobody.
\end{tabular}

The participant talks about the virtual setting in Table 13. She says "[1] There are no walls, no feelings..." She misses even the walls of the classroom [2]. S/he also says that s/he relatively has more freedom with the Adobe Connect in privacy in his/her room at home [3], [4]. S/he feels imprisoned [6] and uses an ironic tone saying: "[7] In these days I think that online classes do not have walls or doors but at least opens a window to us! His/her reference in [8] to "an imaginary classroom" is significant. In [9], s/he lists the features of such a class. It will be individual, private, separated, and isolated. S/he compares such an imaginary classroom to "a FarmVille game application."

Table 13

P1.B. Representation of Memory (The Wall)

Student Excerpt

P1. B. [1] When it comes to the Adobe Connect... There are no walls, no feelings... [2] I did not know before; one day I would miss our dumb walls! [3] In my room, I am sometimes connected via mobile, and sometimes with my computer. [4] There is no such sense. [5] I see the walls of my room with posters on it. [6] I sometimes feel in a cage. [7] In these days I think that online classes do not have walls or doors but at least opens a window to us! [8] May be we will learn to construct an imaginary classroom in our mind. [9] It will be individual, private, separated and isolated of course as is a Farmwill game application. 
The participant tells the story of "his/her desk and seat" in Table 14 and "his/her obsessed habit" in Table 14 to sit always the same place [1], [2] and [8],[9], [10], [11], [12]. S/he gives prominence to involvement in the lessons as $\mathrm{s} /$ he hears better at the front and likes seeing the facial gestures of the teacher when teaching [3]. The narrative part is about the effect of the odour of the red seat. [5] The verbal indicator here is "the wooden perfume" and "the scratched paint" [7]. S/he also tells us about how that desk and seat was part of his/her daily routine in school. S/he uses a stressed possessive adjective: "It was my desk and seat". That the desk is also "his/her "pillow" is as significant as "my own property" and "my home".

Table 14

P1.A. Representation of Memory (The Desk)

\begin{tabular}{ll}
\hline Student & Excerpt \\
\hline P1. A & [1] From my previous classroom, I remember my desk, my best comrade. [2] I am a bit \\
obsessed with the sitting place in the classroom and like sitting at front. [3] I want to see \\
the teacher's face and hear to him/her speaking well. [4] I can only concentrate on my \\
desk, with which we identify in time. [5] I liked the seat's red colour like our doors... and \\
the odour? [6] I still remember and I smell the wooden perfume. The painted layer on the \\
left side of the seat was a bit scratched and the wood is seen. [7] I always got angry with \\
the one who did it but never knew. [8] It was my seat and my desk. [9] It sounds a bit \\
funny but I think I considered it my own property. [10] It was my pillow (sometimes I \\
slept leaning my head on it), it was my table on which I have my sandwich. [11] I feel \\
embarrassed to admit but I even engraved the initial letters of my name. [12] It was as \\
warm as my home.
\end{tabular}

[1], [2], [3] in Table 15 refer to the freedom served by the Adobe Connect classroom but the participant states that $\mathrm{s} /$ he still miss his/her desk and seat [4]. The participant complains that [5] $\mathrm{s} /$ he cannot "see or touch or hear" her friends in this new setting. His/her words "[6] My friends are just names" is significant. [7], [8] repeats the stress on the chatbox, the previous reference to the importance of the chatbox as "emotion box" is made by this participant, too. In [9], [10] s/he expresses his/her desire to see more words in the chatbox so that $\mathrm{s} /$ he could feel as if sitting at "his/her desk".

Table 15

P1.B. Representation of Memory (The Desk)

\begin{tabular}{ll}
\hline Student & Excerpt \\
\hline P1. B & [1] And then comes the Adobe Connect classroom... Sometimes I get connected on the \\
sofa, sometimes on my chair, and sometimes even in my bed. [2] I still cannot explain \\
why my seat and desk was warmer than the one at home? [3] To be honest, it is more \\
comfortable, gives so much freedom, too. [4] Nevertheless, whenever I remember the \\
scratch on my seat, I remember my desk, and then my classroom... [5] I can see or touch \\
or hear nobody in Adobe Connect classroom. [6] My friends are just names. [7] \\
Sometimes I get happy when I feel them when they write in the chat box. [8] Their words \\
are carriers of emotions, I suppose, before they are meaningful. [9] The more friends are \\
writing in the chat the happier I become. [10] I feel as if sitting at my desk.
\end{tabular}

The narratives produced by the participants (narrator-focalizers in the given context) exemplified how classroom setting was transformed into space and how memorization was replaced by memory.

\section{Discussion}

The participants in this study do not only take over the act of narration but also the act of focalisation. These narrating agents emerge as the perceivers of the moments socially and spatially. When these retrospective narrators are talking about the classroom setting, they become 
"focalizers" perceiving the setting and environment "from-within". The long-term memory here is emotionally idiosyncratic in that the participant's reference to the classroom by the name indicates its "particularity" in the episodic memory of the participants. The episodic memory in this context, however, indicates a positive experiential and emotional response, not a traumatic event. The findings imply that the learners should not be entrapped within the two poles of episodic memory and semantic memory. Rather, spatial memory serves as a complementary category in a way that unites the three. The learners develop positive episodic memory in conformity with the semantic function of the setting elements and internalise or personalise the objects in their spatial experience. Concerning the terms collective memory vs individual memory (Byrne et al., 1992, p. 87), it can be said that every object has their own "official accounts" (p. 87) the institutions produce, and unofficial accounts individuals or the marginal groups produce. In this vein, the educational system also determines the collective consciousness about the classroom settings and elements. The participants in this study provide unofficial accounts of the past and represent unpredictable individual consciousness. Byrne et al. (1992) argue that "this focus on the textual mediation of collective memory raises the question of whether collective memory is really a memory at all" (p. 87). The study revealed that harmonious unity of collective memory (objectivity from without) and individual memory (subjectivity from within) is possible.

The classroom is more of a space than a setting, and its existence in the memory of the participants is deeply implanted in this study. The participants' stories reveal emotions as well as comprise the elements of setting, time, characters, point of view and perspective. All these elements consolidate the collective consciousness and individual consciousness, complying with the semantic functions of these objects in the temporal realm. On the other hand, the emotions of the learners are essential, and their stories not only reconstruct the images and events, but also refresh, reproduce, and restore the emotions in the spatial realm. The particular emotions, having been stirred and aroused at the time of the classroom activities in the past, are being reexperienced by the participants while storytelling. The objects are not only a stimulator for concentration but also a stimulator of the memory that flows through the spatial experience of the learner. The participants' references to the colour of the objects indicate that the effect is still vivid. This finding conforms to the field literature (Hutchison, 2004). The participants' insistence on using metaphors shows that the memory is active with a meaningful experience and the classroom lives in the long-term episodic memory of the participants in the form of experienced time or spatial practice. That signifies allegorical function and function of transfer (Ç1rakl1, 2018). The setting is transformed into space, and the spatial experience of the learner is apparent and satisfactory. The objects are restored in the episodic memory, a sign of spatial experience, and rarely revived in the imagination, which makes it possible to restore, refresh, reconsider, rethink, and reconstruct what they were once involved. The participant's story about how the object became a course material reveals that the participant has a spatial experience with the object, which is henceforth a particular object existing in the temporal and spatial realms. The objects are no longer ordinary objects but particular objects of narration. The verbal indicator "an unforgettable moment" articulated in the narratives consolidates the idea.

The narrative accounts of the participants indicate highly self-conscious learners who rethink and reflect upon their experiences. Their literary references like Joyce support previous findings as to memory and memorization, and their focalizing remarks (i.e., smell) show that the interaction with the classroom setting and setting elements transformed into a spatial experience. Regarding the discussions raised by Laursen et al. (2020), the learners need "embodied and affective engagements in the classroom practices" (p. 15). The study foregrounds the significance of the classroom objects and suggests a "shift of emphasis from a focus of located investment toward a focus on placemaking practices of engagement in order to capture the unpredictable and affectively loaded bubbles of becomings that are part of all classroom practices" (p. 15). Not only young learners but also ELL learners are interested in these "bubbles of becomings", which help spatial experience, a result of placemaking. The narratives represent the participant's (the narrator- 
focalizers) emotions and active episodic memory. Signs of sympathy for the objects in the narrative accounts are marked with spatial interaction and spatial experience: "our poor and devoted whiteboard... I feel like smiling...". The emphatic remarks of the participants sound sympathetic and indicate that the object is not only personified but also humanised through spatial experience. That reminds Garnet's study (2020) in a different context. His article "constructs a multivalent account of a student's vandalised violin by utilising a narrative framework to layer various perspectives into an educational history" (p. 648). Garnet (2020) argues that "difficult objects such as these [violin] can provide valuable insights for students and educators alike because of their authenticity, relatability and quite often their ability to inspire empathy" (p. 648). All in all, the setting objects are significant carriers of emotion and objects of empathy; that is, they are the first objective, then subjective correlatives for the participants. The participants' activated - and positive- episodic memories show that the setting is transformed to the experienced time and space. Their references to the major authors from English literature additionally indicate that activated positive episodic memory and spatial experience do not deny or exclude memorization of names, which promises correspondence with semantic memory, which helped the participants restore in mind and interpret them. Moreover, one of the participants tells his/her story of habitual notetaking and implies that $\mathrm{s} /$ he is a self-conscious learner: "Then I have come to realize that my notebook was my classroom." That is a sign of the transformation of the environmental setting to experiential space.

The participants' tone of narration and their recurrent use of focalisation and switch to emotive discourse indicate their need for physical setting as a launching pad for their spatial experience. Of all the narratives, the story about the "wall" seems the most striking one. The readers are presented with a touchy story of touching the wall. As the wall is now an object of the arts, a particular object, the wall in Krashen classroom from the perspective of the participant as narratorfocalizer, the researcher can understand that the classroom setting is transformed into an experienced spatial practice and reconstructed in the form of a story in memory, mind and imagination. Therefore, the classroom setting is a launching pad for social (with the moderator and the other learners) and spatial praxis (with the setting elements). The nature of this interaction is not only social but also "spatial". The stories told by the participants are impressive and represent the authentic moments experienced in the classroom. Almost all the narrative elements are still alive in the narration, and the participant is still excited through recollection. The wall, the dumb and dull environmental setting object, the muted and silenced entity is presented as a personified carrier of emotion (objective correlative) in this example. As McLaren and McKeever (2019) emphasized, the issue of setting calls for a "reconceptualization of the mind as rooted in bodily movement and environmental interaction (p. 60). Similarly, the narrative accounts draw our attention to the relationship with the objects and spatial interaction in the classroom setting. One of the critical ways of experienced spatial practice is that the learners should use these objects in various ways. Creative and responsive activities bring about the spatial experience, or spatial experience encourages creativity in effect. This finding seems to support Lama (2019), who studied "creative networks" and "mapping creativity" in the classroom setting in terms of "design". The most seemingly relevant conclusion raised by the study is that "the creative climate is composed of the circulation of bodies and objects" and that "the role of non-human objects" should be "highlighted" (p. 2). Yet, he still considers "the power of interaction with design classroom tools to promote creativity", which envisages the "non-human actors" within a "creative climate in the classroom" (p. 136). Unfortunately, the study deals with the setting and space as external places and uses them interchangeably and regarding "the classroom space itself as an actor" (p. 136). The present study discusses, however, that setting needs to be spatialized by the touch of human actors (learners), which means "humanisation (Çırakl1, 2018, p. 134). The participants' stories about the objects (i.e., the scratched desk) represent how the ordinary or usual objects become particular carriers of emotion and experience, that is, humanised. The frequent shifts to focalization, for instance, the mention of the "the odour," is critical in this context. Frazier and Bryant (2019), in a 
similar context, states that "relatedly then, sensorimotor experiences may have served as the linchpin between that which signifies and that which is signified". According to Piaget and Inhelder (1956), one's ability to visualize [perceive, sense] an object is dependent on internalizing tactile-kinesthetic experiences with the object; differential sensory-experiences potentially informed the children's [learner's] imagination" (p. 109). Thus, this act of focalization "I [still] smell the wooden perfume" and "the scratched paint" signify the active memory and spatial experience. The participant's purely personal and particular experience and relationship with the objects explain their active mind and long-term memory. The participants' insistent references to home, highlighting the significance of the metonymic relationship between the classroom setting and experienced spatiality, explicate how classroom setting can be reconstructed in memory, mind and imagination.

Bowles and Sendall's (2020) article among few raises the issue of psychological states of the individuals concerning public health education, foregrounding the vulnerability of the students. Bowles and Sendall (2020) discusses the issue of pedagogical adaptations to COVID-19 and highlights cultural differences in pedagogical environments as crucial parameters. Concerning "emergent issues about student engagement and the evidence base for online learning pedagogy" (Bowles \& Sendall, 2020), he calls for a possible adaptation. If this to happen, educators should reconsider the spatial practice in line with memory, mind and imagination as well as "increased social and psychological vulnerability, given that many are isolated" (Bowles \& Sendall, 2020). The narratives by the participants are punctuated with such signs of concerns. Narrator-focalizers radically turn to mere narrators (just telling objectivities, not perceiving subjectivities) when they are talking about the virtual classroom. The narrative accounts about the virtual classroom indicate the active episodic memory in a negative sense and imagination with the metonymic representation of the classroom in mind. The stories about "gaze and monitoring" indicate selfconscious participants and their anxiety. The participants' switch to situational and verbal irony marks a criticism against the current situation, and also refers to the limitations of the tool. The participant seems concerned not only about the efficiency of the classroom but also a hierarchy of "seeing". Their narratives indicate empathy for the image of the lecturer reconstructed in the memory. The mode is rhetorically appealing to emotion rather than intellect, and the objects (i.e., the door) function as semiologic signs of the past experience / spatial experience. They are associated with the previously particular metaphor, metonymy or synecdoche of the overall past experience and the objects are personified. The narrator's reference to "the clock-time", "stress" and "anxiety" of connection is a clue to the obstruction of the memory, mind and imagination. Switches off the mode of focalization "from within" to the mode of description "from without" are significant as psychological stress and exhaustion cause alienation from the tool and setting. The narrator's ironic statement that there is no class at all shows that spatial experience is hardly possible in these cases.

Technology is closer to "clock-time" and cannot create a sense of space which the learners can process into a spatial experience. The participants switch off the focalization mode and become just a narrator telling us about how they are getting connected. The overt comparison between the online classes to the virtual reality of computer or mobile-phone games indicates the vanity of insistence on merely technologically designed virtual classes, which needs humanization. During the virtual sessions, the participants can be involved in the meeting, but it is too transitional to revive in the memory. The learners spend much time connected, but they hardly transform it into a spatial time or experienced time. Their stress on literary works shows that literature courses have the potential to help the students with spatial experience, active memory and creative imagination. These narratives tell us about the effectiveness or disadvantages of the Adobe Connect, emphasizing the use of whiteboard facility, which indicates an aspiration for experientiality. The words "dull and dumb" are literary references to absurd drama, which seems an underlying (maybe unconsciously used) gesture of the void in the educational medium. That the participants are more concerned with/about the practical use of the tool indicates that the virtual setting 
cannot produce emotion which implies that technological gadgets and tools can be useful and efficient temporally, but are hardly able to produce feelings or help to spatialize the experience. That the participants' narrative accounts refer to the factors of efficiency "from without" do not obliterate the participant's needs of emotional contact: "I miss my teacher writing on the board with a terrible board marker about to run out..." Such statements as "Once the virtual session is over, I close my eyes, and I cannot remember any scenes... but the scenes from the pre-COVID-19 classroom" are striking references to the "lack" and imagination needs previous spatial experience. Learners' degree of involvement and frequency of attendance in the virtual sessions may significantly depend on spatial pre-experience. The interested learners with regular attendance, who had spatial experience from the pre-COVID-19 era, can feel relatively more comfortable in the virtual sessions since they can "imagine" a classroom, relying on their previous experience. They can reconstruct and restore the previous classroom setting more readily. This idea is supported by the narratives in T3; the participants are unable to assume or envisage a classroom setting in the absence of the walls. What is significant is that $\mathrm{s} /$ he associates the walls with emotions. This is metonymic again in that the wall stands for the past classroom experience. When the participants tell us about the features of the Adobe Connect classroom, they repeat the temporal parameters of comfort and efficiency. Chu (2020) discusses classroom primarily as a "social organisation" and tries to develop positive psychology for "classroom community" applicable beyond COVID-19 paradigm shift. However, the aspect of setting and space needs crucial re-consideration since the notion of "classroom" has dramatically changed. What remains the same is the human learner, with memory, mind, and imagination and classroom community should be discussed as emerging in the chatboxes or screens. The participants' mode of the complaint as to the lack of humanly touching, however, indicates a prospective difficulty in restoring or reconstructing the setting in memory: "I can see or touch or hear nobody in Adobe Connect classroom. My friends are just names." The narrator also refers to the words as carriers of emotions or emotive responses, which supports the previous findings: "Sometimes I get happy when I feel them when they write in the chatbox. Their words are carriers of emotions, I suppose, before they are meaningful." The participants' narratives about their longing for more friends that appear in the chatbox is a kind of mock-restoring of the classroom setting of the pre-COVID-19 era: "The more friends are writing in the chat, the happier I become. I feel as if sitting at my desk." The participants' stories indicate their emotional need for social and spatial interaction because any word in the chatbox is a sign of emotion, a kind of instrumental speech act in the first place. The researchers should note this, as this raises the question of how the virtual medium can be transformed into more humanly virtual space. Yet, an emotionally spatialized chatbox cannot satisfy the learner's need for spatial interaction.

\section{Conclusions}

All in all, the participants' narratives show that the learners feel more human when they can recollect, restore, reconstruct the classroom setting in the form of refreshed spatial experience in their mind, memory and imagination. Only through spatial experience can a learner activate the memory and experience is reformed continuously, rewritten and reconstructed in the stories. The participants are the first-person narrator-focalizers of these stories, which exemplifies that it is possible to re-experience the past through storytelling. What is more interesting, as is the case with Plato's ideas and forms, without a previous classroom experience that necessarily requires the spatial transformation, the learners cannot set up a learning space and thereby losing their motivation in the distance education. The participants mostly become focalizers when they are talking about spatial experience, while they switch to being only narrators when they are talking about the parameters of efficiency or deficiency concerning the Adobe Connect as a technological tool.

The study has some limitations. The principle of homogeneity, reliability and validity are concerned during the data collection, but the study is limited to time and scope, dealing with a small number of participants. The narratives produced by the volunteer students are grouped 
according to the objects and storytelling elements. Therefore, the study uses a small number of narrative accounts about the selected objects.

\subsection{Implications}

The overall implications of our research point to the significance of carrying out a narrative inquiry into language students' spatial experience within the theory of postromantic education, which argues that unless educational "setting" is transformed into educational 'space', there would be no ground for experience and learning. To this end, the current paper attempted to focus on the spatial interaction of the learners in the conventional classroom setting and online virtual classroom.

One implication of the study is that integration of the theory of pedagogical narratology and instruments of narrative inquiry is required to evaluate the students' small narratives and narrative accounts. The learners' impressions of the objects should be improved through their spatial interaction, and storytelling can be an appropriate means of representation of the spatial experience. The significance of spatial practice in classroom settings is apparently represented in the episodic memories shared by the participants.

Another implication is that current educational studies produce a narrative of "how to teach" and social interaction in the classroom, but the students respond to them at a mode of "reader response". The teachers should reconsider the role of setting and space in teaching and learning and contemplate the prominence of spatial interaction as well as social interaction.

The final implication regarding the study is that students' emotive responses to certain objects (objective and subjective correlatives) in classroom settings and how or to what extent images are received differently by the individual learners need further investigation. Moreover, the study implies that there is a spectrum between the poles of purely official collective consciousness and purely subjective individual consciousness. Between them are a series of shared consciousness and episodic memories.

\subsection{Suggestion for Further Studies}

The idealisation of the past through narrated nostalgia should not be neglected and it may be another topic for further research. Another qualitative research study can be carried out to explore the efficiency of these narratives to increase teachers' and students' awareness of 'spatial interaction". Lastly, when learning activities are restricted to assignments of the writing materials, working on certain reading and writing assignments, the learners are observed to be more productive and more active in online mediums. Recent research shows that student activity in writing tasks significantly increased in writing online courses, and the emotional needs of the students should be reconsidered. For example, an increase from $71.39 \%$ to $75.83 \%$ is yielded through online learning with Google Classroom (Sutrisno, 2020). Spatial interaction, in such cases, can be reconsidered regarding the critical shift in the nature of the setting, medium and objects.

\section{References}

Anderson, C., \& Kirkpatrick, S. (2016). Narrative interviewing. International Journal of Clinical Pharmacy, 38(3) 631-634. https://doi.org/10.1007/s11096-015-0222-0

Bamberg, M., \& Georgakopoulou, A. (2008). Small stories as a new perspective in narrative and identity analysis. Text \& Talk, 28(3), 377-396.

Benson, P. (2014). Narrative inquiry in applied linguistics research. Annual Review of Applied Linguistics, 34, 154-170.

Bolger, N., Davis, A. \& Rafaeli, E. (2003). Diary methods: Capturing life as it is lived. Annual Review of Psychology, 54, 579-616.

Bowles, D. C. \& Sendall, M. C. (2020). COVID-19: The Elephant in the Virtual Classroom. Pedagogy in Health Promotion, 6(3), 156-158. https://doi.org/10.1177/2373379920938419

Bruner, J. S. (1990). Acts of meaning. Cambridge: Harvard University Press. 
Byrne, J. H. \& Eichenbaum, H., Roediger, H. L., Thompson, R. F. (Eds.). (1992). Learning \& Memory (Second Ed.). New York: MacMillan.

Carmona, M., Carmona, S. \& Clarke, W. (2002). The value of good design. London: CABE.

Cheryan, S., Ziegler, S. A., Plaut, V. C., \& Meltzoff, A. N. (2014). Designing classrooms to maximize student achievement. Policy Insights from the Behavioral and Brain Sciences, 1(1), 4-12. https:// doi.org/10.1177/2372732214548677

Clandinin, D. J., \& Huber, J. (2010). Narrative inquiry. In B. McGaw, E. Baker, \& P. P. Peterson (Eds.), International encyclopedia of education (3rd ed.). New York, NY: Elsevier. https://doi.org/10.1016/B978-0-044894-7.01387-7

Coffey, A., \& Atkinson, P. (1996). Making sense of qualitative data, complementary research strategies. London, Thousand Oaks, CA and New Delhi: Sage.

Chu, T.L.A. (2020). Applying positive psychology to foster student engagement and classroom community Amid the COVID-19 Pandemic and Beyond. Scholarship of Teaching and Learning in Psychology. https://doi.org/10.1037/st10000238

Creswell, J. W. (2007). Qualitative inquiry and research design: Choosing among five approaches (2nd ed.). Tousand Oaks, CA: Sage.

Çiraklı, M. Z. (2018). Theory of postromantic education in the postmodernist era: maxims. Journal Narrative and Language Studies, 6(11), 133-136.

Çıraklı, M. Z. (2020). An examination of students and teachers' perceptions of educational setting: representation of space in classroom narratives. 2nd International Language Teacher Education Research Group, Online Conference. Online at: https://e5716c47-a80c-47d5-a634b900c2b16611.filesusr.com/ugd/00f379_ab7ae32ed2004118b4885f34e8624dd2.pdf

Davies, D., Jindal-Snape, D., Collier, C., Digby, R., Hay, P. \& Howe, A. (2013). Creative learning environments in education: A systematic literature review. Thinking Skills and Creativity, 8, 80-91. https://doi.org/10.1016/j.tsc.2012.07.004

Dela Rosa, P. (2019). Physical learning environment on the academic achievement in entrepreneurship of grade 10 students. Universal Acedemic Cluster Project, Southern Luzon State University, Lucban, Quezon.

Demir-Yıldız, C. (2020). Ideal classroom setting for English language teaching through the views of english language teachers (A Sample from Turkey). English Language Teaching, 13(3) 31-44.

Erturan, Y. N., Çevik, R., Gürel, N.A., \& Çağıltay, K. (2012, February). The use of Webinar (virtual classroom) in education: The comparison of commercial (Adobe Connect) and open source (OpenMeetings) Webinar applications. Paper presented at XIV. Academic Informatics Conference, Uşak University, Uşak, Turkey.

Frazier, A. D. \& Bryant, C. (2019). Developing visual-spatial thinking in youth using sensorimotor experiences: Approaches from a Piagetian cognitive framework. Journal of Pedagogical Research, 3(3), 99112.

Garnet, G. (2020). Historying tragedy through an object of empathy: Hon Xuan's Violin. Journal of Art Design, 39 (2), 648-662. https:/ / doi.org/10.1111/jade.12304

Greer, T. (2014). Designing a language classroom. OnCUE Journal, 7(1), 46-52.

Hutchison, D. L. (2004). A natural history of place in education. Columbia University: Teachers College Press.

Kekare, S. (2015). Classroom physical environment and academic achievement of students. International Journal of Indian Psychology, 2(3), 116-120.

Kuzel, A. J. (1992). Sampling in qualitative inquiry. In B. F. Crabtree \& W. L. Miller (Eds.) Research methods for primary care: Doing qualitative research (pp. 31-44). Sage Publications, Inc.

Labov, W. (1972). Sociolinguistic patterns. Philadelphia: University of Pennsylvania Press.

Lama, A. H. (2019). Creative networks: toward mapping creativity in a design classroom. [Doctoral dissertation]. University of North Texas, Denton, Texas

Laursen, H. P., Baun, L. \& Qatergaard, W. (2020). Bubbles of becomings: from located investment to placemaking practices of engagement in the language classroom. Language and Education. Advanced online publication. http://www.doi.org/10.1080/09500782.2020.1775247

Le Goff, J. (1992). History and memory. New York: Columbia University Press.

Leimanis-Wyat, M. (2010) Classroom DIY: A practical step-by-step guide to setting up a creative learning environment. London: Routledge.

McLaren, C. \& McKeever, P. (2019). Dancing bodies, moving spaces: revealing children's movement encounters in an integrated kindergarten classroom. Performance Matters, 5(1), 60-80. 
Mira, R. G., Camaselle, J. M., \& Martínez, J. R. (2003). Culture, environmental action and sustainability. Hogrefe \& Huber Publishing.

Miles, M. B., \& Huberman, A. M. (1994). Qualitative data analysis (2nd ed.). Thousand Oaks, CA: Sage.

Mishler, E.G. (1995). Models of narrative analysis: a typology. Journal of Narrative and Life History, 5(2), 87123. https:// doi.org/10.1075/jnlh.5.2

Nambiar, R.M.K., Nor, N.M., Kemboja, I., \& Adam, S. (2017). New learning spaces and transformations in teacher pedagogy and student learning behavior in the language learning classroom. The Southeast Asian Journal of English Language Studies, 23(4) 29- 40. https:/ / doi.org/10.17576/3L-2017-2304-03

Piaget, J., \& Inhelder, B. (1956). The child's conception of space. London: Routledge \& Kegan Paul.

Polkinghorne, D. (1988). Narrative knowing and the human sciences. Albany: SUNY Press

Randall, M. (2007). Memory, psychology and second language learning. Language Learning \& Language Teaching. John Benjamin's Publishing Company.

Reissman, C. K. (2008). Narrative methods for human sciences. CA, USA: Sage

Smith, C. P. (2000). Content analysis and narrative analysis. In H. T. Reis \& C. M. Judd (Eds.), Handbook of research methods in social and personality psychology (p.313-335). Cambridge University Press.

Stadler-Altmann, U. (2015). Learning Environment: The Influence of School and Classroom Space on Education. In C. Rubie-Davies, J. M. Stephens, P. Watson (Eds.). The Routledge International Handbook of Social Psychology of the Classroom (pp. 547-571). Routledge.

Sutrisno, S. (2020). Increased Learning Activities and Outcomes through Online Learning with Google Classroom in the Covid-19 Pandemic Period. Ideguru: Jurnal Karya Ilmiah Guru,5(1), 95. https://doi.org/10.51169/ideguru.v5i1.151

Şen, B., Atasoy, F., \& Aydın, N. (2010, February). Low cost web based distance education System application. Paper presented at XII. Academic Informatics Conference, Muğla University, Muğla, Turkey.

Urtil, J. A. S. (2016). Nature of classroom environment as a source of variation in grade 10 science class. (Masters' Thesis). Southern Luzon State University, Lucban, Quezon.

Viner, R. M, Russell S. J., Croker, H., Packer J., Ward J., \& Stansfield C., (2020). School closure and management practices during coronavirus outbreaks including COVID-19: a rapid systematic review. Lancet Child Adolescent Health, 4, 397-404. https:// doi.org/10.1016/S2352-4642(20)30095-X

Warner, S. A., \& Myers, K. L. (2010). The creative classroom: the role of space and place toward facilitating creativity. Technology Teacher, 69(4), 28-34.

Wixted, J. T. \& Serences, J. T. (Eds). (2018). Stevens' handbook of experimental psychology and cognitive neuroscience fourth edition: Sensation, Perception, \& Attention (4th ed., Volume 2). New York: Wiley.

Woolner, P. (2010). The design of learning spaces. Continuum, London.

Yıldız, S. \& Çakır, S. (2013). Evaluation of Classroom Design in terms of Foreign Language Learning. Procedia - Social and Behavioral Sciences, 83, 277-281. https://doi.org/10.1016/j.sbspro.2013.06.054 